\title{
Encyclopedia of Planetary Landforms
}



Henrik Hargitai - Ákos Kereszturi Editors

\section{Encyclopedia of Planetary Landforms}

With 1862 Figures and 11 Tables

Springer Reference 
Editors

Henrik Hargitai

NASA Ames Research Center/NPP

Moffett Field, CA, USA

\author{
Ákos Kereszturi \\ Konkoly Thege Miklos Astronomical \\ Institute, Research Centre for Astronomy \\ and Earth Sciences \\ Budapest, Hungary
}

ISBN 978-1-4614-3133-6

ISBN 978-1-4614-3134-3 (eBook)

ISBN 978-1-4614-3135-0 (print and electronic bundle)

DOI 10.1007/978-1-4614-3134-3

Springer New York Heidelberg Dordrecht London

Library of Congress Control Number: 2015934230

(C) Springer Science+Business Media New York 2015

This work is subject to copyright. All rights are reserved by the Publisher, whether the whole or part of the material is concerned, specifically the rights of translation, reprinting, reuse of illustrations, recitation, broadcasting, reproduction on microfilms or in any other physical way, and transmission or information storage and retrieval, electronic adaptation, computer software, or by similar or dissimilar methodology now known or hereafter developed.

The use of general descriptive names, registered names, trademarks, service marks, etc. in this publication does not imply, even in the absence of a specific statement, that such names are exempt from the relevant protective laws and regulations and therefore free for general use.

The publisher, the authors and the editors are safe to assume that the advice and information in this book are believed to be true and accurate at the date of publication. Neither the publisher nor the authors or the editors give a warranty, express or implied, with respect to the material contained herein or for any errors or omissions that may have been made.

Printed on acid-free paper

Springer Science+Business Media LLC New York is part of Springer Science+Business Media (www.springer.com) 


\section{Acknowledgments}

In addition to section editors and authors, several other workers contributed to the encyclopedia in many ways. The editors would like to thank and acknowledge the following reviewers for their valuable comments or suggestions to improve the quality of particular entries and the overall structure of the encyclopedia during the 5 years of its making: Steve Ackley, Mate Adamkovics, Phil Ashworth, Joshua Bandfield, David R. Bridgland, Debra L Buczkowski, Titusz Bugya, Jean-Pierre Burg, Alain Burgisser, Jennifer Burnham, Helene Burningham, William Cassidy, Anna Chanou, Bernd Christiansen, Stefania Cocco, R.A. Craddock, Ian Crawford, Neil Davies, Christopher Edwards, Kevin Ray Evans, Alberto G. Fairen, Carl T. Friedrichs, Arnold Gucsik, W.R. Halliday, Weon Shik Han, Tanya Harrison, Kenneth Herkenhoff, Thomas Holzer, Debra Hurwitz, Richard M. Iverson, Matt Izawa, Jason Janke, Greg Jennings, Molly Johnson, Pierre Y. Julien, Pieter Jungerius, Linda C. Kah, Lars Kaleschke, Marek Kasprzak, Stephanie Kermode, Ross Kerr, Randolph Kirk, Christian Koeberl, Yves Langevin, Andrew Lea-Cox, Yangxiaoyi Lu, David Marchant, Steve Martel, Brandon McElroy, Sarah M. Milkovich, Diana Miller, Stephen J. Mojzsis, Francis Nimmo, Eirini Papadaki, Howard Perko, Cedric Pilorget, Laura Pioli, Sylvain Piqueux, Sebastien Rodriguez, C.H. Scholz, Steven Simon, Kelsi Singer, Isaac Smith, A. Szakács, Tamás Telbisz, Peter Thomas, Matthew Tiscareno, Jim Trexler, Haim Tsoar, Jens M. Turowski, Antonio Turtù, Skip Walker, Andrew Warren, Giles Wiggs, Jean-Pierre Williams, and Whyjay Zheng.

We would also like to thank the following workers of the publisher Springer, who helped realize the encyclopedia online and in print between 2010 and 2015 (in alphabetical order): Mary Baker, USA; Jennifer Carlson, USA; Megan Ernst, USA; Elizabeth Ferrell, USA; Annalea Manalili, USA; Banupriya Mohanraj, India; Lydia Mueller, Germany; Maury Solomon, USA. 



\section{Note on the Different Conceptual Types of Entries}

This encyclopedia provides a snapshot of our current knowledge on the geological features on solid-surface Solar System bodies. They extend over a wide range of scales, from micrometers (e.g., $>$ microcrater) to global scales (e.g., - Martian hemispheric dichotomy), and include landform types (structural or topographic features), parts of landforms, terrain types or surface textures, surface patterns, and features identified at wavelengths extending from visible to radio waves (e.g., $>$ albedo feature, $>$ thermal infrared feature, $>$ radar feature).

Depending on the information and formation models available, the entries have different approaches. Some discuss their subject from the point of view of the inferred process or origin (e.g., $\triangleright$ sedimentary rocks [Mars], $\triangleright$ esker); others are morphology or description based (e.g., > light-toned deposit, - sinuous ridge). As a default, entries focus on extraterrestrial landforms while also mentioning their proposed terrestrial analogues (e.g., $\triangleright$ triangular scar [Mars], > solifluction-like lobes [Mars]). While most planetary landforms are not body specific (e.g., > strike-slip fault), others have no known terrestrial counterparts (e.g., $>$ softened crater, $>$ corona). If the formation model of a certain planetary feature is not yet well developed or is under extensive debate, the entry focuses on a terrestrial landform (i.e., its potential terrestrial analogue), is based on its better established formation model, and gives examples of proposed locations of such features elsewhere (e.g., > esker, > seamount, \ snow features, $\triangleright$ solifluction landforms). There are no entries about particular (individual) landforms unless they are unique and form a class by themselves ( $\triangleright$ stealth feature (radar, Mars)).

We also included very few landforms that are found only on Earth and/or are generally related to biogenic processes. We did this as there is a plausible chance that similar landforms may potentially be produced by nonbiogenic processes elsewhere (e.g., abiogenic induration of $>$ parabolic dunes instead of the effect of vegetation). Named historic (obsolete) landform types are also included to provide reference for previous papers.

To make it easier to find features with related origins, from page CXV we list landforms based on their formative processes (e.g., $>$ aeolian features). We also included entries on the IAU descriptor terms (e.g., > catena, catenae). 



\section{Notes}

\section{Notes on Images}

All images that appear in this volume have been contrast-enhanced. A majority of the image mosaics is map projected, presented with north to the top, in cylindrical equidistant projection centered at the center of the image.

Distribution of landforms are shown on the following background maps, unless otherwise stated.

Basemap of Mercury: MESSENGER mosaic (NASA/Johns Hopkins University Applied Physics Laboratory/Carnegie Institution of Washington)

Basemap of Venus: Magellan radar mosaic and shaded relief from Magellan radar altimetry (Venus Global GUS DVD NASA/USGS)

Basemap of Earth: ETOPO1 Global Relief Model (NOAA, Amante C, Eakins BW [2009] ETOPO1 1 Arc-Minute Global Relief Model: Procedures, Data Sources and Analysis. NOAA Technical Memorandum NESDIS NGDC-24, 19 pp)

Basemap of the Moon: LRO WAC Albedo and Shaded Relief from LRO LOLA DEM (NASA/USGS)

Basemap of Mars: TES Albedo (Christensen et al. [2001] The Mars Global Surveyor Thermal Emission Spectrometer experiment: Investigation description and surface science results. J Geophys Res 106:23, 823-823, 871) and shaded relief from MOLA topography (NASA)

Basemap of Io: Voyager/Galileo mosaic (NASA/USGS/Björn Jónsson)

Basemap of Europa: Voyager/Galileo mosaic (NASA/USGS/Björn Jónsson)

Basemap of Titan: Cassini radar and infrared mosaic (NASA/JPL/Cassini RADAR team)

(Map editor for all maps: H. Hargitai) 
New Year dates $\left(\mathrm{Ls}=\mathbf{0}^{\circ}\right)$ on Mars

MY (Cantor et al. 2010)

\begin{tabular}{ll}
\hline 20 & $01-04-1991$ \\
\hline 21 & $11-21-1992$ \\
\hline 22 & $10-09-1994$ \\
\hline 23 & $08-26-1996$ \\
\hline 24 & $07-14-1998$ \\
\hline 25 & $05-31-2000$ \\
\hline 26 & $04-18-2002$ \\
\hline 27 & $03-05-2004$ \\
\hline 28 & $01-21-2006$ \\
\hline 29 & $12-09-2007$ \\
\hline 30 & $10-26-2009$ \\
\hline 31 & $09-13-2011$ \\
\hline 32 & $07-31-2013$ \\
\hline 33 & $06-18-2015$ \\
\hline 34 & $05-05-2017$ \\
\hline 35 & $03-23-2019$ \\
\hline 36 & $02-07-2021$ \\
\hline 37 & $12-26-2022$ \\
\hline 38 & $11-12-2024$ \\
\hline 39 & $09-30-2026$ \\
\hline 40 & $08-17-2028$ \\
\hline
\end{tabular}

\section{Adjectives}

\begin{tabular}{ll}
\hline Callisto & Callistoan, Callistan \\
\hline Calypso & Calypsonian \\
\hline Ceres & Cererean, Cerian \\
\hline Charon & Charonian \\
\hline Deimos & Deimian \\
\hline Earth & Terrestrial, Terran \\
\hline Enceladus & Enceladan, Enceladean \\
\hline Eris & Eridian \\
\hline Eros & Erotian \\
\hline Europa & Europan \\
\hline Ganymede & Ganymedean \\
\hline Iapetus & Iapetian, Japetian \\
\hline Io & Ionian \\
\hline Juno & Junonian \\
\hline Jupiter & Jovian \\
\hline Mars & Martian \\
\hline Mercury & Mercurian, Hermean \\
\hline Mimas & Mimantean \\
\hline Moon & Lunar \\
\hline Neptune & Neptunian \\
\hline Nix & Nictian \\
\hline Phobos & Phobian \\
\hline Pluto & Plutonian \\
\hline & \\
\hline
\end{tabular}




\begin{tabular}{ll}
\hline Saturn & Kronian, Saturnian \\
\hline Sun & Solar \\
\hline Titan & Titanian \\
\hline Uranus & Uranian \\
\hline Venus & Cytherean, Venusian, Venerian \\
\hline Vesta & Vestalian, Vestian \\
\hline
\end{tabular}

\section{References}

Aubry M-P, Van Couvering JA, Christie-Blick N, Landing E et al (2009) Terminology of geological time: Establishment of a community standard. Stratigraphy 6(2):100-105

Cantor BA, James PB, Calvin WM (2010) MARCI and MOC observations of the atmosphere and surface cap in the north polar region of Mars. Icarus 208(1):61-81

Clancy RT, Sandor BJ, Wolff MJ, Christensen PR, Smith MD, Pearl JC, Conrath BJ, Wilson RJ (2000) An intercomparison of ground-based millimeter, MGS TES, and Viking atmospheric temperature measurements' seasonal and interannual variability of temperatures and dust loading in the global Mars atmosphere. J Geophys Res 105(E4):9553-9571. doi:10.1029/1999JE001089

Moore HJ, Hutton RE, Clow GD, Spitzer CR (1987) Physical properties of the surface materials at the Viking landing sites on Mars. U.S. Geological Survey Professional Paper 1389 



\section{List of Acronyms, Abbreviations and Other Symbols}

\# Abstract number

- See also cross-reference

[ ] IAU descriptor term entry title in square brackets: Singular or plural form of an IAU descriptor term approved but not assigned to any feature as to 2014

ASI Agenzia Spaziale Italiana - Italian Space Agency

ASU Arizona State University, Tempe AZ

BMDO Ballistic Missile Defense Organization

cf Compare

CICLOPS Cassini Imaging Central Laboratory For Operations, SSI

CIW Carnegie Institution of Washington, Washington, DC

CNES Centre Nationale d' Etudes Spatiales, Paris, France

Cornell Cornell University, Ithaca, NY

CTX Context Camera onboard MRO

DLR Deutsches Zentrum für Luft- und Raumfahrt - German Aerospace Center, Berlin, Germany

EO-1 NASA Earth Observing-1 mission

EPSC European Planetary Science Conference

ESA European Space Agency

ESP Extended Science Phase (2009-), in HiRISE image IDs

FMAP Full-resolution radar map

F-MIDR Full-Resolution Mosaicked Image Data Record (Magellan)

FU Berlin Freie Universität Berlin

Ga Billion year ago (Giga annum) (Aubry et al. 2009)

GSFC Goddard Space Flight Center, Greenbelt, MD

Gyr Billion year (duration) (Aubry et al. 2009)

HiRISE High Resolution Imaging Science Experiment onboard MRO

HRSC High Resolution Stereo Camera onboard Mars Express

IAU International Astronomical Union

IBCAO International Bathymetric Chart of the Arctic Ocean

IDA Institut für Datentechnik und Kommunikationsnetze, TU

Braunschweig - Institute of Computer and Communication Network

Engineering, Braunschweig, Germany

IMP Imager for Mars Pathfinder

ISS International Space Station

JAXA Japan Aerospace Exploration Agency 
JHUAPL Johns Hopkins University, Applied Physics Laboratory,

Laurel, MD

JPL Jet Propulsion Laboratory, Pasadena, CA

JSC Johnson Space Center, Houston, TX

LPGNantes Laboratoire de Planétologie et Géodynamique, Université de Nantes, France

LPI Lunar and Planetary Institute, Houston, TX

LPS Lunar and Planetary Science Conference, Houston, TX (1995-2008

[26-39])

LPSC Lunar and Planetary Science Conference, Houston, TX (1979-1994 [9-25], 2009- [40-])

LRO Lunar Reconnaissance Orbiter

LRO WAC Lunar Reconnaissance Orbiter Wide Angle Camera

Ls Solar longitude. Ls refers to the aerocentric longitude of the Sun (i.e., the sub-solar longitude on Mars), and is an hemisphere-independent means of referring to the season on Mars based on Mars' orbital position. Ls $=0^{\circ}$ is the spring (vernal) equinox. (e.g., Moore et al. 1987, p. 17)

LSC Lunar Science Conference, Houston, TX (1970-1978 [1-8])

Ma Million year ago (Aubry et al. 2009)

MDIS Mercury Dual Imaging System onboard MESSENGER

MESSENGER MErcury Surface, Space ENvironment, GEochemistry, and Ranging

MEX Mars Express

MGS Mars Global Surveyor

MOC Mars Orbiter Camera onboard MGS

MOLA Mars Orbiter Laser Altimeter onboard MGS

MPS or MPI Max Planck Institute for Solar System Research

(Max-Planck-Institut für Sonnensystemforschung), Lindau, Germany

MRO Mars Reconnaissance Orbiter

MSSS Malin Space Science Systems, San Diego, CA. Images provided courtesy of Malin Space Science Systems. For more information, please contact Malin Space Science Systems at www.mssss.com

MY Mars Year. It is an arbitrary numbering of Mars years with year 1 beginning April 11 (vernal equinox), 1955, defined by Clancy et al. (2000). The correspondence between Mars years, terrestrial dates, and Ls values between 1955 and 2029 is given in Cantor et al. (2010)

Myr Million year (duration) (Aubry et al. 2009)

NASA National Aeronautics and Space Administration

NGA National Geospatial-Intelligence Agency, Springfield, VA

NOAA National Oceanic and Atmospheric Administration, Washington, DC

NSIDC National Snow and Ice Data Center, Boulder, CO

PDS Planetary Data System

PSP Primary Science Phase (2006-2008), in HiRISE image IDs

RADAR Cassini Radio Detection and Ranging instrument, also former acronym for Radio Detection and Ranging (radar)

SAR Synthetic Aperture Radar

SRI Southwest Research Institute, San Antonio, TX

SSI Space Science Institute, Boulder, CO 
TES Thermal Emission Spectrometer onboard MGS

THEMIS Thermal Emission Imaging System onboard Mars Odyssey THEMIS Day IR Thermal Emission Imaging System daytime infrared global mosaic

UA, UoA The University of Arizona, Tucson, AZ

UC University of Colorado, Boulder, $\mathrm{CO}$

UCLA University of California, Los Angeles, CA

USGS U.S. Geological Survey, Flagstaff, AZ

USNRL U.S. Naval Research Laboratory, Washington, DC 



\section{Editors-in-Chief}

Henrik Hargitai (Ph.D., 2007) is a planetary geomorphologist and media historian. He is a postdoctoral fellow at the NASA Ames Research Center. He taught planetary geomorphology, planetary cartography, typography, and media history as a senior lecturer at Eötvös Loránd University, Budapest, Hungary since 2002. He has a Ph.D. in Earth Sciences and Philosophy (Aesthetics). His study fields include planetary cartography, fluvial geomorphology, and the history and localization of planetary nomenclature. He participated in two Mars Desert Research Station simulations. He is the chair of the ICA Commission on Planetary Cartography. He is the producer of numerous public outreach programs in planetary science for the radio and a member of the Beautiful Mars project.

Ákos Kereszturi (Ph.D.) is a geologist working on planetary science and astrobiology as researcher at the Research Centre for Astronomy and Earth Sciences, where he leads the Astrophysical and Geochemical Laboratory. He is member of the NASA Astrobiology Institute TDE Focus Group, teaches planetary science at Eötvös Loránd University, serves on the editorial board of one national and two international journals, is vice president of the Hungarian Astronomical Association, and contributes in the popularization activity of the Polaris Observatory in Budapest. His main research area is the geology of Mars, Europa satellite, craters of Mercury, water in the solar system and beyond, Mars analog field work, survival of extremophile organisms, analysis of asteroid surfaces, and geological history based on mineral characteristics of meteorites. 



\section{Editorial Board}

Serina Diniega Ph.D. is a mathematical planetary geomorphologist. She is Scientist and Science Systems Engineer at the Jet Propulsion Laboratory, California Institute of Technology. Her research focuses on modeling and analyzing landform evolution on Earth and Mars (including dunes and dune fields, lava flows and features, and gullies) and aims to interpret the history of regional processes and environmental conditions from remote images of planetary surfaces. In addition, she supports large-scale science efforts within the Mars Science Community through the NASA Mars Program Office and has supported mission operations for the Mars Reconnaissance Orbiter. She is a regular reviewer for several journals and participates as often as she is able in public and student outreach activities.

Ernst Hauber is a planetary geologist at the Institute of Planetary Research in Berlin, Germany, which is part of the German Aerospace Center (DLR). He studies the solid surfaces of terrestrial planets, with a focus on endogenic processes (volcanism, tectonism) and on sedimentary, glacial, and periglacial landforms, including fieldwork on terrestrial analogues. He is coinvestigator of several deep space experiments and leads the HRSC Geoscience Working Group. Ernst Hauber is a member of the ExoMars Landing Site Selection Working Group, the ESA-NASA iMARS Team (International Mars Architecture for the Return of Samples), and ESA's Planetary Protection Working Group and served as a member of the ESA/NASA Joint Science Working Group (JSWG) on the 2018 Joint Rover Mission. He has received an ESA award for his involvement in the Mars Express mission. He is a regular reviewer for several journals and has also served on several grant review panels.

Brian M. Hynek Ph.D. is Associate Professor in the Department of Geological Sciences and Laboratory of Atmospheric and Space Physics, both at the University of Colorado-Boulder, USA. He earned a B.A. in Earth Sciences from the University of Northern Iowa and an M.A. and Ph.D. from Washington University in St. Louis. His main research studies are focused on the hydrologic, geologic, and climatic histories of Mars, and he approaches these problems through geologic mapping, modeling, experiments, and analog studies of similar processes occurring on Earth. He is also Director of the University of Colorado Center for Astrobiology. 
Ralf Jaumann (Doctoral Degree Munich 1989; Habilitation Munich 2003) is a geologist. He is head of the Planetary Geology section of the DLR Institute of Planetary Research in Berlin and Professor of Planetology at the Free University of Berlin. His involvement in space missions comprises instrument development as well as scientific investigations for the exploration of Mars (NASA Pathfinder, ESA Mars Express mission, ESA ExoMars mission), Saturn (NASA/ESA Cassini/Huygens mission, ESA JUICE Mission), Venus (ESA Venus Express mission), Comets (ESA Rosetta mission), and Asteroids (NASA Dawn mission, JAXA/DLR Mascot/Hayabusa II mission). His research concerns the origin and evolution of planetary bodies, the composition of planetary surfaces, and geologic processes in the solar system.

Jarmo Korteniemi is a planetary geomorphologist and a professional science journalist. He earned his degree in astronomy/planetology (M.Sc., 2005) from the University of Oulu (UO), Finland, and specialized in the interaction of glacial, fluvial, and volcanic processes on Mars. He worked in the Mars Express HRSC Team at both UO and the German Aerospace Center (DLR Berlin), and spent research periods at the University of Münster, the Lunar and Planetary Institute, and the University of California in Santa Cruz. Urged by the poor understanding of science in science journalism, he switched over to the Master's Degree Programme in Science Communication at UO. He now specializes in reasoned journalism and popularizing scientific research. He continues planetary research as a founding member of the Arctic Planetary Science Institute, Finland.

Andrey A. Lukashov received his D.Sc. degree in 1990. Since 1993, he is Professor in the Faculty of Geography at Lomonosov Moscow State University. Since 2010, he is Distinguished Professor at MSU. His current research and research interest focuses on structural geomorphology and morphotectonics, especially of rifts, karst, morphology of volcanic regions, problems of comparative planetology, and geomorphological prospecting of mineral deposits. Prof. Lukashov has delivered a number of lecture courses in geomorphology, geology, and geochemistry at Russian, Ukrainian, and Kazakh universities. He has published 190 works including maps and 7 monographs.

Nicolas Mangold (Ph.D., 1997) is Research Director at the Laboratory of Planetology and Geodynamics at the University of Nantes. He is a geologist working on the evolution of planetary surfaces, with a special focus on the planet Mars and the role of water in its surface processes. In 2006, he received the CNRS (Centre national de la recherche scientifique) Bronze Medal for his work on fluvial and glacial landforms on Mars. He is an investigator of the European mission Mars Express and contributes especially to the interpretations of data of OMEGA and HRSC instruments by correlating mineralogy from infrared spectra with geology from optical images. He is also part of the Curiosity rover science team and will participate in future orbital and in situ investigations of Mars through the ExoMars rover from ESA and the 2020 rover from NASA. He has also served on journal editorial boards and the advisory committee at CNRS. 
Philip Stooke is a cartographer and planetary scientist in the Department of Geography and the Centre for Planetary Science and Exploration at the University of Western Ontario. He obtained his Ph.D. from the University of Victoria in British Columbia, where he developed methods for mapping nonspherical objects such as asteroids, and he has compiled photomosaic maps of many planetary satellites, asteroids, and comet nuclei. He has compiled several reference books, including The International Atlas of Lunar Exploration (Cambridge, 2007), The International Atlas of Mars Exploration (Cambridge, 2012), and a second Mars volume following the rover missions and Phoenix due to be published in 2015. He has also published papers on the history of lunar and planetary mapping.

James R. Zimbelman is a planetary geologist at the Center for Earth and Planetary Studies (CEPS), National Air and Space Museum (NASM), Smithsonian Institution. Dr. Zimbelman has been a research geologist at NASM since 1988. He conducts research related to volcanic and aeolian (wind-surface interactions) processes and landforms on Earth and the terrestrial planets (particularly Mars) and the preparation of geologic maps of Mars and Venus. His research is reported in peer-reviewed literature in more than 80 journal articles, book chapters, and published geologic maps. In 2000, he coedited the book Environmental Effects on Volcanic Eruptions: From Deep Oceans to Deep Space (Kluwer Academic/Plenum Publishers) and is coauthor with Ralph Lorenz of the book Dune Worlds: How windblown sand shapes planetary landscapes (Springer/Praxis), which was published in May 2014. He was elected a GSA Fellow in 1999 and was awarded the 2013 Ronald Greeley Award for Distinguished Service by the Planetary Geology Division of GSA. 



\section{Contributors}

Stephen H. Anderson Department of Soil, Environmental, and Atmospheric Sciences, University of Missouri, Columbia, MO, USA

Jeffrey C. Andrews-Hanna Colorado School of Mines, Golden, CO, USA

Irene Antonenko Planetary Institute of Toronto, Toronto, ON, Canada

J. Ramón Arrowsmith School of Earth and Space Exploration, Arizona State University, Tempe, AZ, USA

James W. Ashley Jet Propulsion Laboratory, California Institute of Technology, Pasadena, CA, USA

Andreas C. W. Baas Department of Geography, King's College London, London, UK

David M. H. Baker Department of Geological Sciences, Brown University, Providence, RI, USA

John P. Balfour Centre for Glaciology Institute of Geography and Earth Sciences, Aberystwyth University, Aberystwyth, UK

Matthew Balme Department of Physical Sciences, The Open University Walton Hall, Milton Keynes, UK

Maria E. Banks Center for Earth and Planetary Studies, Smithsonian Institution, National Air and Space Museum, Washington, DC, USA

Planetary Science Institute, Tucson, AZ, USA

David Baratoux Geosciences Environnement Toulouse, Université de Toulouse III - Observatoire Midi-Pyrénées, Toulouse, France

Nadine G. Barlow Department of Physics and Astronomy, Northern Arizona University, Flagstaff, AZ, USA

Gabriella Barta Department of Physical Geography, Eötvös Loránd University, Institute of Geography and Earth Sciences, Budapest, Hungary

Patricio Becerra Lunar and Planetary Laboratory, The University of Arizona, Tucson, AZ, USA

Szaniszló Bérczi Department of Materials Physics, Eötvös Loránd University, Institute of Physics, Budapest, Hungary 
Ana M. Bernabeu Department of Marine Geosciences, University of Vigo, Vigo, Spain

Walter Bertoldi Department of Civil, Environmental and Mechanical Engineering, University of Trento, Trento, Italy

Ananya Biswas Department of Earth Sciences, Indian Institute of Engineering Science and Technology (IIEST), Formerly Bengal Engineering and Science University, Shibpur, India

Leslie F. Bleamaster III Center for the Sciences and Innovation, Trinity University, San Antonio, TX, USA

Planetary Science Institute, Tucson, AZ, USA

David T. Blewett The Johns Hopkins University Applied Physics Laboratory, Laurel, MD, USA

Nataliya Bondarenko University of California - Santa Cruz, Santa Cruz, CA, USA

Michael J. Bovis Department of Geography, University of British Columbia, Vancouver, BC, Canada

Joseph M. Boyce Hawaii Institute of Geophysics and Planetology, University of Hawaii, Honolulu, HI, USA

Brittany D. Brand Geosciences, Boise State University, Boise, ID, USA

Veronica J. Bray Lunar and Planetary Laboratory, University of Arizona, Tucson, AZ, USA

Petr Brož Institute of Geophysics, Academy of Sciences of the Czech Republic, Prague, Czech Republic

Tamás Börzsönyi Institute for Solid State Physics and Optics, Wigner Research Centre for Physics, Budapest, Hungary

M. H. K. Bulmer Geophysical Flow Observatory Joint Center for Earth Systems Technology with NASA GSFC, University of Maryland, Baltimore County, MD, USA

Paul K. Byrne Lunar and Planetary Institute, Universities Space Research Association, Houston, TX, USA

Jeffrey M. Byrnes Boone Pickens School of Geology, Oklahoma State University, Stillwater, OK, USA

Edgardo Cañón-Tapia Centro de Investigación Científica ca y de Educación Superior de Ensenada, Ensenada, Baja California, Mexico

Marco Cardinale Laboratorio di Telerilevamento e Planetologia, Dipartimento di Scienze Psicologiche, Umanistiche e del Territorio, Università degli Studi G. D’Annunzio, Chieti, Italy

Paul A. Carling Geography and Environment, University of Southampton, Southampton, UK 
Vincenzo Cataldo School of Earth and Space Exploration, Arizona State University, Tempe, AZ, USA

Giacomo Certini Dipartimento di Scienze delle Produzioni Agroalimentari e dell'Ambiente (DISPAA), Università degli Studi di Firenze, Florence, Italy

Mirona Chirienco Science and Technology Group, Okinawa Institute of Science and Technology, Onna-son, Okinawa, Japan

Matthew Chojnacki Lunar and Planetary Laboratory, University of Arizona, Tucson, AZ, USA

Mathieu Choukroun Jet Propulsion Laboratory, California Institute of Technology, Pasadena, CA, USA

Frank C. Chuang Planetary Science Institute, Tucson, AZ, USA

Jonathan Clarke Geoscience Australia, Canberra, ACT, Australia

Gareth S. Collins Department of Earth Science and Engineering, Imperial College London, London, UK

Susan J. Conway Department of Physical Sciences, The Open University, Milton Keynes, UK

Thomas Cornet European Space Agency (ESA), European Space Astronomy Centre (ESAC), Villanueva de la Cañada, Madrid, Spain

Kathleen L. Craft Space Exploration Sector, The Johns Hopkins University Applied Physics Laboratory, Laurel, MD, USA

Giovanni B. Crosta Department of Earth and Environmental Sciences, Università degli Studi di Milano Bicocca, Milan, Italy

J. Brad Dalton III Planetary Ices Group, NASA-Jet Propulsion Laboratory, Pasadena, CA, USA

Ingrid Daubar University of Arizona, Tucson, AZ, USA

Rene De Hon Department of Geography, Texas State University, San Marcos, TX, USA

Ashley Gerard Davies Jet Propulsion Laboratory, California Institute of Technology, Pasadena, CA, USA

Fabio Vittorio De Blasio Department of Earth and Environmental Science, University of Milan Bicocca, Milan, Italy

Serina Diniega Jet Propulsion Laboratory, California Institute of Technology, Pasadena, CA, USA

John C. Dixon Department of Geosciences, University of Arkansas, Fayetteville, AR, USA

Andrew Dombard Department of Earth and Environmental Sciences, University of Illinois at Chicago, Chicago, IL, USA 
Nathan B. Drake Department of Physics, Austin College, Sherman, TX, USA

Sarah A. Drummond Natural and Behavioral Sciences, Pellissippi State and Technical Community College, Knoxville, TN, USA

Lauren Edgar U.S. Geological Survey, Astrogeology Science Center, Flagstaff, AZ, USA

Hicham Elbelrhiti Département des Sciences Fondamentales et Appliquées (DSFA), Institut Agronomique et Vétérinaire Hassan II, Rabat, Morocco

Mohamed Ramy El-Maarry Physikalisches Institut, Bern Universität, Bern, Switzerland

P. G. Eriksson Department of Geology, University of Pretoria, Pretoria, South Africa

Gino Erkeling Institut für Planetologie, Westfälische WilhelmsUniversität, Münster, Germany

Richard E. Ernst Department of Earth Sciences, Carleton University, Ottawa, ON, Canada

Francesca Esposito INAF-Osservatorio Astronomico di Capodimonte, Naples, Italy

Amy Fagan USRA Lunar and Planetary Institute, Houston, TX, USA

Western Carolina University, Cullowhee, NC, USA

Caleb Fassett Department of Astronomy, Mount Holyoke College, South Hadley, MA, USA

James Fastook School of Computing and Information Science, and Climate Change Institute, University of Maine, Orono, ME, USA

Carlos Fernández Departamento de Geodinámica y Paleontología, Universidad de Huelva, Huelva, Spain

David A. Ferrill Department of Earth, Material, and Planetary Sciences, Geosciences and Engineering Division, Southwest Research Institute, San Antonio, TX, USA

Thierry Feuillet Laboratoire LETG-Nantes-Géolittomer, CNRS, Nantes, France

Justin Filiberto Department of Geology, Southern Illinois University Carbondale, Carbondale, IL, USA

Kathryn E. Fitzsimmons Department of Human Evolution, Max Planck Institute for Evolutionary Anthropology, Leipzig, Germany

Emóke Fodor Department of Physical Geography, Institute of Geography and Earth Sciences, Eötvös Loránd University, Budapest, Hungary

Elizabeth A. Frank Department of Terrestrial Magnetism, Carnegie Institution of Washington, Washington, DC, USA 
Kirstie Fryirs Department of Environment and Geography, Macquarie University, Sydney, NSW, Australia

Lisa Gaddis U.S. Geological Survey, Astrogeology Science Center, Flagstaff, AZ, USA

Péter Gadányi Nyugat-magyarországi Egyetem, Földrajzés Környezettudományi Intézet, Szombathely, Hungary

Gerald A. Galgana Lunar and Planetary Institute, USRA, Houston, TX, USA

Colman Gallagher UCD School of Geography, Planning and Environmental Policy, University College, Belfield, Dublin, Ireland

Rebecca Ghent Department of Earth Sciences, University of Toronto, Toronto, ON, Canada

Bernd Giese Planetary Geodesy, German Aerospace Center, Institute of Planetary Research, Berlin, Germany

Jeffrey Gillis-Davis Hawaii Institute of Geophysics and Planetology, University of Hawaii, Honolulu, HI, USA

D. C. Golden ESCG\ARESWNASA, Houston, TX, USA

Rita González-Villanueva Coast, Water and Surface Processes Research Group, Universidade de Lisboa, Faculdade de Ciências, Instituo Dom Luiz, Lisbon, Portugal

Richard Greenberg Lunar and Planetary Laboratory, University of Arizona, Tucson, AZ, USA

Tracy K. P. Gregg Department of Geology, University at Buffalo, Buffalo, NY, USA

Peter Grego British Astronomical Association/Society for Popular Astronomy, St Austell, Cornwall, UK

Carlos H. Grohmann Institute of Energy and Environment, University of São Paulo, Brazil, São Paulo, Brazil

Eric B. Grosfils Geology Department, Pomona College, Claremont, CA, USA

Luca Guallini Physics Institute, Space Research and Planetary Sciences, University of Bern, Bern, Switzerland

IRSPS, Università d'Annunzio, Pescara, Italy

Magnús T. Gudmundsson Nordic Volcanological Center, Institute of Earth Sciences, University of Iceland, Reykjavík, Iceland

Evgeniya N. Guseva Vernadsky Institute, Moscow, Russia

David E. Haddad School of Earth and Space Exploration, Arizona State University, Tempe, AZ, USA 
Justin J. Hagerty United States Geological Survey, Astrogeology Science Center, Flagstaff, AZ, USA

Timothy Haltigin Space Exploration Development, Canadian Space Agency, Saint-Hubert, QC, Canada

Vicki L. Hansen Department of Earth and Environmental Sciences, University of Minnesota, Duluth, MN, USA

Henrik Hargitai NASA Ames Research Center/NPP, Moffett Field, CA, USA

Alexander G. Hayes Astronomy Department, Cornell University, Ithaca, NY, USA

Jennifer L. Heldmann Division of Space Sciences and Astrobiology, NASA Ames Research Center, Mountain View, CA, USA

Paul Helfenstein Center for Radiophysics and Space Research, Cornell University, Ithaca, NY, USA

Doug Hemingway University of California, Santa Cruz, CA, USA

ElSayed Hermas Geography Department, Umm Al-Qura University, Makkah Al-Mukkarramah, Kingdom of Saudi Arabia

Robert R. Herrick Geophysical Institute, University of Alaska, Fairbanks, AK, USA

György Hetényi Department of Earth Sciences, ETH Zurich, Zurich, Switzerland

Trudi Hoogenboom Hagen Lunar and Planetary Institute, Houston, TX, USA

Donald M. Hooper Geosciences and Engineering Division, Southwest Research Institute, San Antonio, TX, USA

Mihály Horányi Laboratory for Atmospheric and Space Physics and Department of Physics, University of Colorado, Boulder, CO, USA

Briony Horgan Department of Earth, Atmospheric, and Planetary Sciences, Purdue University, West Lafayette, IN, USA

Jun Huang Planetary Science Institute, China University of Geosciences, Wuhan, P. R. China

Chris H. Hugenholtz Department of Geography, University of Calgary, Calgary, AB, Canada

Scott S. Hughes Department of Geosciences, Idaho State University, Pocatello, ID, USA

Brian M. Hynek Department of Geological Sciences, Laboratory for Atmospheric and Space Physics, University of Colorado, Boulder, CO, USA

Erzsébet Illés-Almár Konkoly Thege Miklos Astronomical Institute, Research Centre for Astronomy and Earth Sciences, Budapest, Hungary 
Mikhail Ivanov Vernadsky Institute, Russian Academy of Sciences, Moscow, Russia

Derek Jackson Environmental Sciences Research Institute, School of Environmental Sciences, University of Ulster, Coleraine, County Londonderry, UK

Martin P. A. Jackson Bureau of Economic Geology, Jackson School of Geosciences, The University of Texas at Austin, Austin, TX, USA

Felix Jagert Geography Department, Geomatics/Remote Sensing Group, Ruhr-University, Bochum, Germany

Ralf Jaumann DLR, Institut für Planetenforschung, Berlin, Germany

Andreas Johnsson Department of Earth Sciences, University of Gothenburg, Gothenburg, Sweden

William Robert Johnston Space Vehicles Directorate, Air Force Research Laboratory, Kirtland AFB, NM, USA

Bradley L. Jolliff Department of Earth and Planetary Sciences and the McDonnell Center for the Space Sciences, Washington University, Saint Louis, MO, USA

Donna M. Jurdy Earth and Planetary Sciences, Northwestern University, Evanston, IL, USA

Dávid Karátson Department of Physical Geography, Eötvös Loránd University, Budapest, Hungary

Péter Kardeván Department of Environmental Geology, Geological and Geophysical Institute of Hungary, Budapest, Hungary

Ákos Kereszturi Konkoly Thege Miklos Astronomical Institute, Research Centre for Astronomy and Earth Sciences, Budapest, Hungary

Seung-Sep Kim Department of Geology and Earth Environmental Sciences, Chungnam National University, Yuseong-gu, Daejeon, South Korea

Young-Seog Kim Department of Earth and Environmental Sciences, Pukyong National University, Busan, South Korea

Christian Klimczak Department of Terrestrial Magnetism, Carnegie Institution of Washington, Washington, DC, USA

Department of Geology, University of Georgia, Athens, GA, USA

Erika Kohler Arkansas Center for Space and Planetary Sciences, University of Arkansas, Fayetteville, AR, USA

Goro Komatsu International Research School of Planetary Sciences, Università d'Annunzio, Pescara, Italy

Jarmo Korteniemi Earth and Space Physics, Department of Physics, University of Oulu, Oulu, Finland 
Arctic Planetary Science Institute, Rovaniemi, Finland

Veli-Petri Kostama Department of Physics/Astronomy, University of Oulu, Oulu, Finland

Michelle R. Koutnik Department of Earth and Space Sciences, University of Washington, Seattle, WA, USA

János Kovács Department of Geology and Meteorology, University of Pécs, Pécs, Hungary

Michael Küppers European Space Astronomy Centre, European Space Agency, Villanueva de la Cañada, Madrid, Spain

Georgiana Kramer Lunar and Planetary Institute, Houston, TX, USA

Mikhail A. Kreslavsky Earth and Planetary Sciences, University of California, Santa Cruz, CA, USA

P. Senthil Kumar CSIR - National Geophysical Research Institute, Hyderabad, India

Julie Laity Department of Geography, California State University, Northridge, CA, USA

Nicholas Lancaster Division of Earth and Ecosystem Sciences, Desert Research Institute, Reno, NV, USA

Mirjam Langhans Earth's Magnetic Field, GFZ German Research Centre for Geosciences, Potsdam, Germany

Phillip H. Larson Department of Geography, Minnesota State University, Mankato, MN, USA

Alice Le Gall LATMOS (Laboratoire Atmosphères, Milieux, Observations Spatiales), UVSQ (Université Versailles Saint-Quentin), Paris, France

Alexandra Lefort Department of Earth and Planetary Sciences, The University of Tennessee, Knoxville, TN, USA

Raffaello Lena Geologic Lunar Research (GLR) Group, Rome, Italy

Giovanni Leone Department of Earth Sciences (Erdwissenschaften), Institute of Geophysics, Swiss Federal Institute of Technology (ETH Zurich), Zurich, Switzerland

Tsafrir Levi Division of Engineering Geology and Geological Hazards, The Geological Survey of Israel (GSI), Jerusalem, Israel

Joseph Levy Institute for Geophysics, University of Texas, Austin, TX, USA

Zac Yung-Chun Liu Department of Geological Sciences, Brigham Young University, Provo, UT, USA

Dénes Lóczy Institute of Geography, University of Pécs, Pécs, Hungary 
Iván López Área de Geología, Universidad Rey Juan Carlos, Madrid, Spain

Bart Makaske Soil Geography and Landscape Group, Wageningen University, Wageningen, The Netherlands

Kathleen Mandt Space Science and Engineering, Southwest Research Institute, San Antonio, TX, USA

Nicolas Mangold Laboratoire de Planétologie et Géodynamique de Nantes, Université de Nantes/CNRS, Nantes, France

Simone Marchi Southwest Research Institue, Boulder, CO, USA

Robert Markley Department of English, University of Illinois, Urbana, USA

Matteo Massironi Dipartimento di Geoscienze and CISAS, Università degli Studi di Padova, Padova, Italy

Audeliz Matias Center for Distance Learning, SUNY Empire State College, Saratoga Springs, NY, USA

Norikazu Matsuoka Faculty of Life and Environmental Sciences, University of Tsukuba, Ibaraki, Japan

Jan-Hendrik May School of Earth and Environmental Sciences, University of Wollongong, Wollongong, Australia

Danny McCarroll Department of Geography, Swansea University, Wales, UK

William B. McKinnon Department of Earth and Planetary Sciences, Washington University in St. Louis, Saint Louis, MO, USA

Moses P. Milazzo Astrogeology Team, U.S. Geological Survey, Flagstaff, AZ, USA

Katarina Miljković Department of Earth, Atmospheric and Planetary Sciences, Massachusetts Institute of Technology, Cambridge, MA, USA

Susan W. S. Millar Department of Geography, Syracuse University, Syracuse, NY, USA

David R. Montgomery Department of Earth and Space Sciences, University of Washington, Seattle, WA, USA

Joanna Morgan Department of Earth Science and Engineering, Imperial College London, London, UK

Sarah Morrison Lunar and Planetary Laboratory, University of Arizona, Tucson, AZ, USA

Balázs Nagy Department of Physical Geography, Eötvös Loránd University, Budapest, Hungary 
Amanda L. Nahm Department of Geological Sciences, University of Idaho, Moscow, ID, USA

Akiko M. Nakamura Department of Planetology, Kobe University, Nada, Kobe, Japan

Clément Narteau Institut de Physique du Globe de Paris, Sorbonne Paris Cité, Univ Paris Diderot, CNRS, France

Marius Necsoiu Geosciences and Engineering Division, Southwest Research Institute, San Antonio, TX, USA

Károly Németh Institute of Agriculture and Environment, Volcanic Risk Solutions, Massey University, Palmerston North, New Zealand

Stefano Nerozzi Institute for Geophysics, The University of Texas at Austin, Austin, TX, USA

Sarah Noble Astrochemistry, NASA Goddard Space Flight Center, Greenbelt, MD, USA

Riko Noormets The University Centre in Svalbard (UNIS), Longyearbyen, Svalbard, Norway

Jason Nycz Department of Geoscience, University of Calgary, AB, Canada

Dorothy Z. Oehler Mars Science Laboratory Participating Scientist, LZ Technology/Jacobs JETS Contract, Astromaterials Research and Exploration Science Directorate, Johnson Space Center, Houston, TX, USA

Teemu Öhman Arctic Planetary Science Institute, Rovaniemi, Finland

Lujendra Ojha Lunar and Planetary Laboratory, University of Arizona, Tucson, AZ, USA

O. J. Okafor Department of Geology, University of Pretoria, Pretoria, South Africa

Jens Ormö Centro de Astrobiología, Instituto Nacional de Tecnica Aeroespacial, Madrid, Spain

Flora Paganelli Spatial Sciences Institute, Allan Hancock Foundation, University of Southern California, Los Angeles, CA, USA

David Page Department of Physical Sciences, The Open University, Milton Keynes, UK

Colin Pain MED_Soil, University of Seville, Seville, Spain

Alexey A. Pankine Space Science Institute, Pasadena, CA, USA

Robert Pappalardo Jet Propulsion Laboratory, California Institute of Technology, Pasadena, CA, USA

Reid Allen Parsons NASA Ames Research Center, Moffet Field, CA, USA 
Eric J. R. Parteli Institute for Multiscale Simulation, Friedrich-AlexanderUniversität Erlangen-Nürnberg, Erlangen, Germany

G. Wesley Patterson The Johns Hopkins University, Applied Physics Laboratory, Laurel, MD, USA

D. Alex Patthoff Planetary Science Division, Jet Propulsion Laboratory, California Institute of Technology, Pasadena, CA, USA

Gro Birkefeldt Møller Pedersen Nordic Volcanological Center, Institute of Earth Sciences, University of Iceland, Iceland

Aurel Perşoiu Stable Isotope Laboratory, Ştefan cel Mare University, Suceava, Romania

J. Taylor Perron Massachusetts Institute of Technology, Cambridge, MA, USA

Taronish M. Pithawala Department of Earth Sciences, University of Toronto, Toronto, ON, Canada

Jeffrey B. Plescia The Johns Hopkins University, Applied Physics Laboratory, Laurel, MD, USA

Monica Pondrelli International Research School of Planetary Sciences, Università d'Annunzio, Pescara, Italy

Ganna Portyankina Laboratory for Atmospheric and Space Physics, University of Colorado Boulder, Boulder, CO, USA

George Postma Faculty of Geosciences, Earth Science Department, Utrecht University, Utrecht, The Netherlands

Ross Potter Department of Earth, Environmental and Planetary Sciences, Brown University, Providence, RI, USA

Center for Lunar Science and Exploration, USRA-Lunar and Planetary Institute, Houston, TX, USA

Laramie V. Potts Department of Engineering Technology, New Jersey Institute of Technology, Newark, NJ, USA

Jani Radebaugh Department of Geological Sciences, Brigham Young University, Provo, UT, USA

Wolf Uwe Reimold Museum für Naturkunde Berlin and Humboldt University Berlin, Berlin, Germany

Daniel Rey Department of Marine Geosciences, University of Vigo, Vigo, Spain

Alyssa Rose Rhoden Johns Hopkins University, Applied Physics Laboratory, Laurel, MD, USA

Edward Rhodes Department of Geography, The University of Sheffield, Sheffield, UK 
Derek C. Richardson University of Maryland at College Park, College Park, MD, USA

Cory Rieth Department of Psychology, University of California, San Diego, CA, USA

Stuart Robbins Southwest Research Institute, Boulder, CO, USA

James H. Roberts Applied Physics Laboratory, The Johns Hopkins University Applied Physics Laboratory, Laurel, MD, USA

David A. Rothery Department of Physical Sciences, Open University, Milton Keynes, UK

Belén Rubio Department of Marine Geosciences, University of Vigo, Vigo, Spain

Steven W. Ruff Mars Space Flight Facility, School of Earth and Space Exploration, Arizona State University, Tempe, AZ, USA

Kirby Runyon The Johns Hopkins University, Baltimore, MD, USA

Hazen A. J. Russell Geological Survey of Canada, Ottawa, ON, Canada

Andrew J. Ryan School of Earth and Space Exploration, Arizona State University, Tempe, AZ, USA

Ted Scambos National Snow and Ice Data Center/CIRES, University of Colorado at Boulder, Boulder, CO, USA

Paul M. Schenk Lunar and Planetary Institute, Houston, TX, USA

Norbert Schörghofer Institute for Astronomy, University of Hawaii at Manoa, Honolulu, HI, USA

Antoine Séjourné UMR8148, GEOPS, Univ Paris-Sud, CNRS, Orsay, France

Michelle Selvans Center for Earth and Planetary Studies, National Air and Space Museum, Smithsonian Institution, Washington, DC, USA

Priyanka Sharma Jet Propulsion Laboratory, California Institute of Technology, Pasadena, CA, USA

David R. Sharpe Geological Survey of Canada, Ottawa, ON, Canada

Vladislav V. Shevchenko Department of Lunar and Planetary Research, Sternberg State Astronomical Institute, Moscow, Russia

Heiner Siedel TU Dresden, Institute of Geotechnical Engineering, Dresden, Germany

András Sik Department of Physical Geography, Eötvös Loránd University, Budapest, Hungary

Simone Silvestro Carl Sagan Center, SETI Institute, Mountain View, CA, USA 
E. L. Simpson Department of Physical Sciences, Kutztown University, Kutztown, PA, USA

John L. Smellie Department of Geology, University of Leicester, Leicester, UK

Richard Soare Department of Geography, Dawson College, Montreal, QC, Canada

Colin Souness Institute of Geography and Earth Sciences, Aberystwyth University, Aberystwyth, Ceredigion, Wales, UK

Kathryn M. Stack Geophysics and Planetary Geosciences, Jet Propulsion Laboratory, California Institute of Technology, Pasadena, CA, USA

Thiago Statella Instituto Federal de Educação, Ciência e Tecnologia de Mato Grosso, Cuiabá, Mato Grosso, Brazil

Katrin Stephan Planetary Geology, German Aerospace Center, Institute of Planetary Research, Berlin, Germany

John A. Stevenson School of GeoSciences, Grant Institute, The University of Edinburgh, Edinburgh, UK

Chris R. Stokes Department of Geography, Durham University, Durham, UK

Julie D. Stopar School of Earth and Space Exploration, Arizona State University, Tempe, AZ, USA

Robert D. Storrar School of Geography, Queen Mary University of London, London, UK

Esther Stouthamer Department of Physical Geography, Utrecht University, Utrecht, The Netherlands

Seiji Sugita Department of Earth and Planetary Science, University of Tokyo, Tokyo, Japan

Robert Sullivan Center for Radiophysics and Space Research, Cornell University, Ithaca, NY, USA

Darrel A. Swift Department of Geography, University of Sheffield, Sheffield, UK

Tímea Szabó Department of Mechanics, Materials and Structures, Budapest University of Technology and Economics, Budapest, Hungary

Anna A. Szynkiewicz Earth and Planetary Sciences, University of Tennessee, Knoxville, TN, USA

Jennifer Taylor School of Earth Sciences, University of Bristol, Bristol, UK

Daniela Tirsch German Aerospace Center (DLR), Institute of Planetary Research, Berlin, Germany 
Anita Torabi Uni Research CIPR, Bergen, Norway

David Trang Hawai'i Institute of Geophysics and Planetology, University of Hawai'i at Mānoa, Honolulu, HI, USA

Fiorenzo C. Ugolini Dipartimento di Scienze delle Produzioni Agroalimentari e dell'Ambiente (DISPAA), Università degli Studi di Firenze, Florence, Italy

Andrew Valdez Great Sand Dunes National Park and Preserve, Mosca, CO, USA

Carolyn H. van der Bogert Institut für Planetologie, Westfälische Wilhelms-Universität Münster, Münster, Germany

Stephan van Gasselt Planetary Sciences and Remote Sensing, Institute of Geological Sciences, Freie Universitaet Berlin, Berlin, Germany

John G. Van Hoesen Department of Environmental Studies, Green Mountain College, Poultney, VT, USA

Federico Vilas Department of Marine Geosciences, University of Vigo, Vigo, Spain

Péter Várkonyi Budapest University of Technology and Economics, Budapest, Hungary

Roland J. Wagner German Aerospace Center (DLR), Institute of Planetary Research, Berlin, Germany

Lisa S. Walsh Center for Earth and Planetary Studies, National Air and Space Museum, Smithsonian Institution, Washington, DC, USA

Dave Waltham Department of Earth Sciences, Royal Holloway, University of London, Egham, Surrey, UK

Jessica Watkins Department of Earth, Planetary, and Space Sciences, University of California, Los Angeles, CA, USA

Wesley Andres Watters Whitin Observatory, Wellesley College, Wellesley, MA, USA

Matt B. Weller Earth Science, Rice University, Houston, TX, USA

Stephanie C. Werner Comparative Planetology, Centre for Earth Evolution and Dynamics, University of Oslo, Oslo, Norway

W. Brian Whalley School of Geography, Queen's University Belfast, Belfast, UK

Oliver White NASA Ames Research Center, MS 245-3, Moffett Field, CA, USA

Rebecca Williams Planetary Science Institute, Tucson, AZ, USA

Sharon A. Wilson Center for Earth and Planetary Studies, Smithsonian Institution, National Air and Space Museum, Washington, DC, USA 
Christian Wöhler Image Analysis Group, TU Dortmund University, Dortmund, Germany

Jim Zimbelman National Air and Space Museum, Center for Earth and Planetary Studies, Smithsonian Institution, Washington, DC, USA

Angelo Zinzi ASI Science Data Center/INAF - Osservatorio Astronomico di Roma, Rome, Italy 